\title{
Sclerosing stromal tumour of ovary
}

\section{Chitrawati B. Gargade ${ }^{1 *}$, Abhay Y. Desai ${ }^{2}$, Dnyaneshwar C. Shirsat ${ }^{3}$}

\author{
${ }^{1}$ Department of Pathology, BKL Walawalkar Rural Medical College, Derwan, Maharashtra, India \\ ${ }^{2}$ Department of Surgery, BKL Walawalkar Rural Medical College, Derwan, Maharashtra, India \\ ${ }^{3}$ Department of Obstetrics and Gynaecology, BKL Walawalkar Rural Medical College, Derwan, Maharashtra, India
}

Received: 30 March 2016

Accepted: 27 April 2016

\section{*Correspondence:}

Dr. Chitrawati B. Gargade,

E-mail: chitragargade@yahoo.com

Copyright: () the author(s), publisher and licensee Medip Academy. This is an open-access article distributed under the terms of the Creative Commons Attribution Non-Commercial License, which permits unrestricted non-commercial use, distribution, and reproduction in any medium, provided the original work is properly cited.

\begin{abstract}
Sclerosing stromal tumor is rare benign ovarian sex cord stromal tumour which occurs predominantly in the 2 nd and 3rd decades of life. We report a case of a 32-year-old woman who presented with irregular menstruation and pelvic pain. She underwent panhysterectomy as USG revealed a solid and cystic $15 \mathrm{~cm}$ right ovarian tumour with increased vascularity with raised CA125. Hysterectomy specimen revealed a benign sclerosing stromal tumour of right ovary. We present this rare case to emphasis the awareness of benign sclerosing stromal tumour of ovary in young female to avoid unnecessary extensive surgery.
\end{abstract}

Keywords: Ovary, Sclerosing stromal tumour, Benign

\section{INTRODUCTION}

Sclerosing stromal tumor (SST) is a rare benign ovarian sex cord stromal tumour with prevalence of $1.5 \%$ to $6 \%$ of ovarian stromal tumors. ${ }^{1}$ It occurs predominantly in the $2^{\text {nd }}$ and $3^{\text {rd }}$ decades of life. More than $80 \%$ of SSTs occur in patients below the age of thirty years. ${ }^{2}$

Few cases have been reported in postmenopausal female. ${ }^{3}$ SST causes menstrual irregularities. Some are hormonally active and can cause virilisation, hirustism and rarely endometrial carcinoma.

\section{CASE REPORT}

A 32years old woman presented with complaints of menstrual irregularities and pelvic pain for six months. Ultrasound (USG) showed a heterogeneous apparently solid mass of $18 \times 9 \mathrm{~cm}$ dimension with some cystic foci in right ovary. Her CA-125 was raised. She was suspected to have a malignant tumor on radiological examination and underwent pan-hysterectomy.
The right adnexa showed encapsulated $19 \times 15 \times 8 \mathrm{~cm} . \mathrm{cm}$ oval mass with attached fallopian tube on its surface. The outer surface was smooth and intact. Cut section was greyish white solid and cystic with mucoid appearance (Figure 1). Focal areas of hemorrhage were seen. Multiple sections from solid and cystic areas on microscopy showed sclerosing stromal tumour of ovary showing ill-defined cellular lobules separated by edematous and myxoid stroma (Figure 2).

Nodules show dual population of cells; spindle cells (Figure 3) and round cells with vacuolated cytoplasm and round to oval nuclei (Figure 4). Mitotic figures are absent. Tumour shows many thin walled ectatic blood vessels, few like in haemangiopericytoma (Figure 5). On immunohistochemistry, MIB-1 index is $1-2 \%$ inhibin and calretinin, EMA are negative. Some of the cells show SMA positivity.

Though he immunohistochemistry results are not completely helpful, final diagnosis of Sclerosing stromal tumour was made on light microscopy findings. 


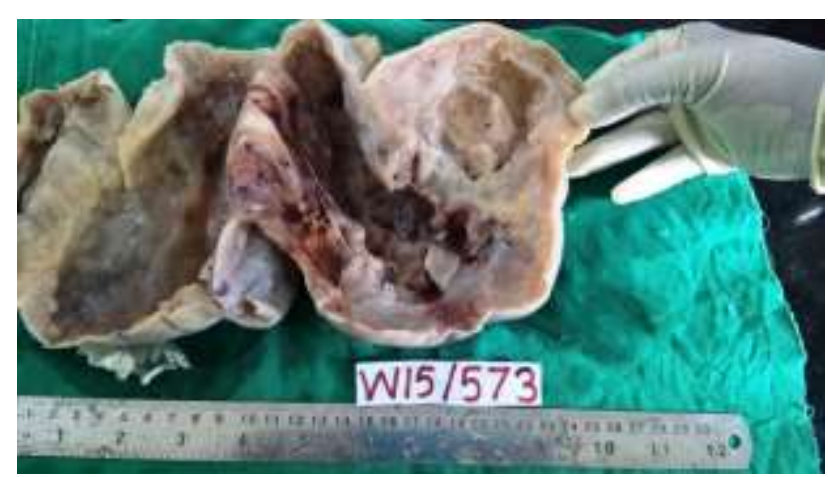

Figure 1: Ovarian mass showing solid, grey-white tumour with mucinous and cystic change.

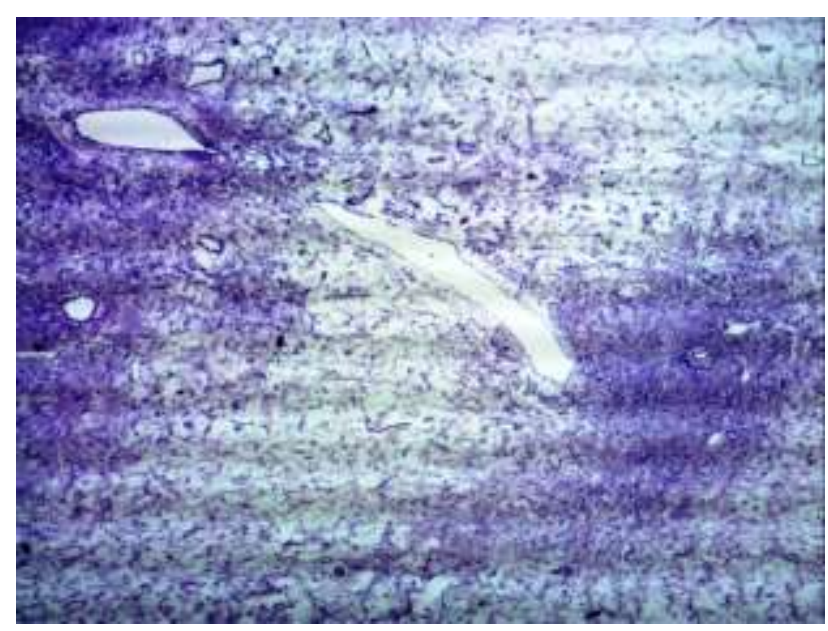

Figure 2: Pseudolobular pattern of alternating hyper and hypocellular areas (H\&E 40X).

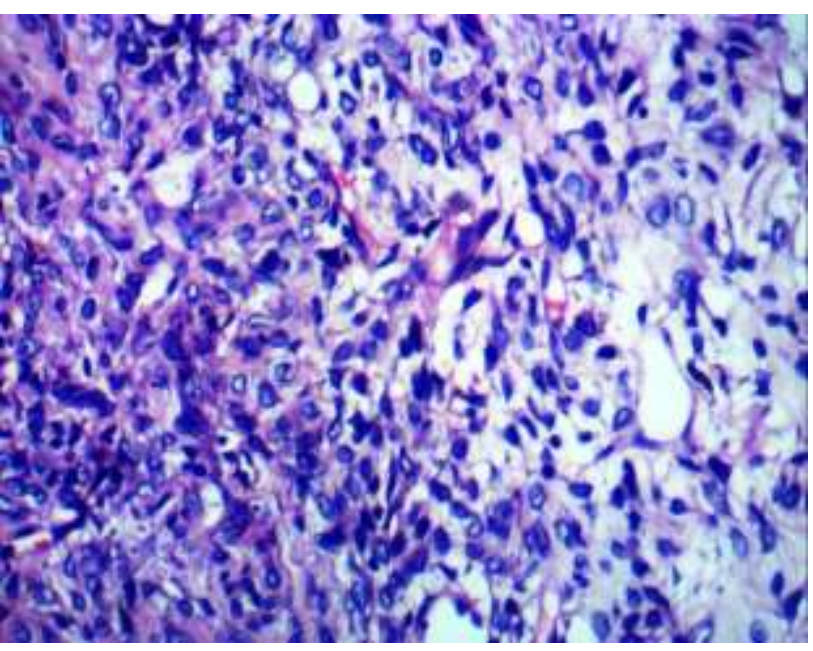

Figure 3: Spindle cells (H\&E 400X).

\section{DISCUSSION}

Chalvardjian and Scully first described SSTs as a distinct disease entity in ovarian sex cord stromal tumors. SST is a rare benign ovarian stromal tumor which has distinctive clinical and histological characteristics. It is prevalent in young age groups and has heterogeneous cellular patterns, which distinguish it from the fibroma, thecoma and other types of ovarian stromal tumors. ${ }^{4}$

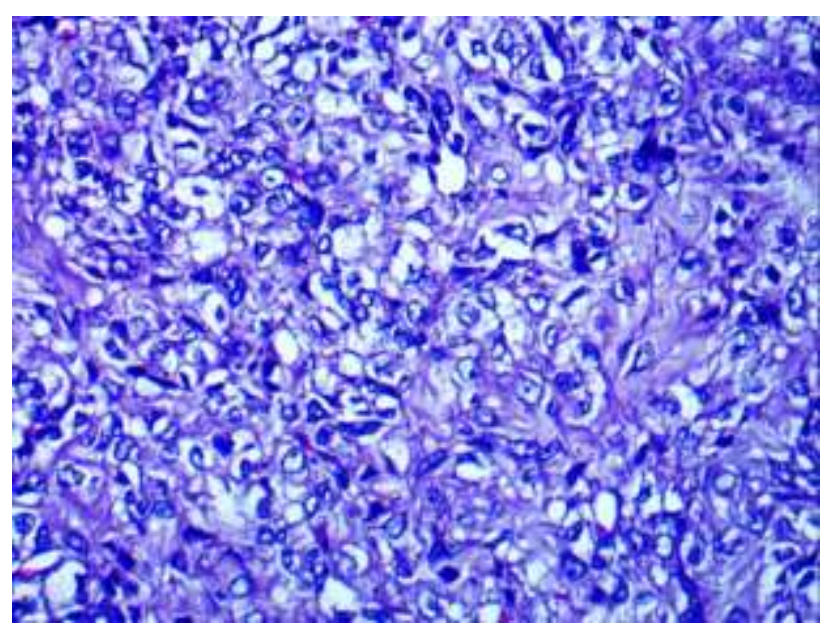

Figure 4: Round cells with clear cytoplasm (H\&E 400X).

Sclerosing stromal tumor is rare benign tumor predominantly seen in young women. The SSTs are unilateral tumors predominantly affecting females in the second and third decades; however few cases have been reported in adolescent girls ${ }^{6}$ and postmenopausal women. ${ }^{5,7,8}$

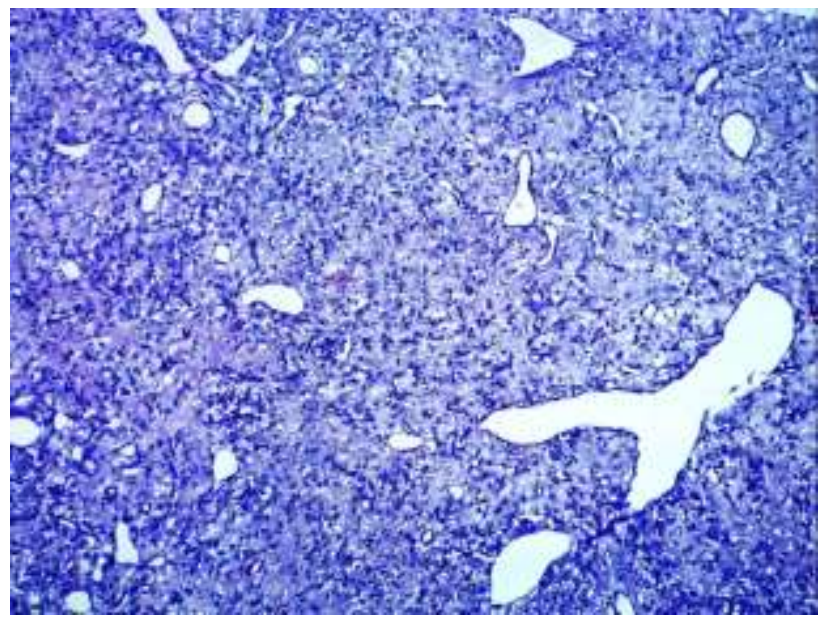

Figure 5: Thin-walled and hemangiopericytoma-like vessels (H\&E 100X).

SSTs are typically unilateral with bilateral presentation reported in only two cases. ${ }^{9}$

Most of SSTs encountered to date have been benign. ${ }^{10}$ Conservative surgery should be performed and correct intraoperative diagnosis is important in young females with characteristic imaging features.

The common presenting symptoms of SST include menstrual irregularity, pelvic pain while rarely presents with virilisation or masculinisation. ${ }^{11,} 12$ No clinical virilisation seen in our case. 
In patients with SST, serum CA-125 levels have been found to be either elevated or within reference ranges. ${ }^{6}$ Our patient had elevated CA125 level.

A significant linear correlation between volume of pleural effusion and serum Ca125 values has been demonstrated in both benign and malignant diseases. ${ }^{13}$ Similar correlation has been demonstrated between CA125 elevation and volume of ascites in Meigs syndrome. Our patient had a raised level of CA125 of 98 $\mathrm{IU} / \mathrm{ml}$ with mild ascites and pleural effusion.

On ultrasound examination SST usually appears as a solid lesion but could be cystic with increased peripheral vascularity on colour Doppler. Early and strong peripheral enhancement is a key characteristic feature in distinguishing between SSTs and other types of sex cord stromal tumors. ${ }^{14}$

The histopathology of the SST shows a pseudolobular pattern of cellular areas and hypocellular, edematous or collagenous areas. It has a prominent vasculature and prominent sclerosis around clusters of individual cells as well as cellular heterogeneity of the vacuolated luteinized theca-like cells and spindle shaped fibroblast-like cells in the cellular areas. ${ }^{4}$

Immunohistochemical, the cells of SSTs are positive for vimentin, smooth muscle actin, $\alpha$-inhibin, and CD99; and are negative for S-100 protein and epithelial markers. ${ }^{15}$

The characteristic histopathological features we observed in our study are usually adequate for the diagnosis of SSTs.

The differential diagnosis of ovarian SSTs incorporates other sex cord-stromal tumors.

- Fibromas and the comas have distinct histopathological findings and do not show pseudolobular pattern.

- Haemangiopericytoma like pattern may lead to diagnosis of some vascular tumour but inhibin positivity suggests the diagnosis of SST.

- Massive ovarian edema may be confused with SST. But preserved ovarian tissue within the edematous stroma and absence of heterogeneity favors the diagnosis of massive ovarian edema.

- Krukenberg tumors are one of the differential diagnoses and can be ruled out by absence of mitotic activity and nuclear atypia and presence of lipid instead of mucin instead of in vacuolated cells.

Surgical resection of the tumour is the primary treatment modality for SSTs and usually have excellent prognosis with dramatic reversal of hormonal effects. In our case there was no recurrence seen in last six months six months duration may be less to know the recurrence.

\section{CONCLUSION}

Though SST is a rare tumor, it should be considered in young woman with menstrual irregularity and hypervascular solid cystic adnexal mass. In such cases frozen section may be helpful in preserving fertility by avoiding extensive surgery.

\section{Funding: No funding sources}

Conflict of interest: None declared

Ethical approval: The study was approved by the Institutional Ethics Committee

\section{REFERENCES}

1. Young RH. Sex cord-stromal tumors of the ovary and testis: their similarities and differences with consideration of selected problems. Mod Pathol. 2005;18:S81-98.

2. Saitoh A, Tsutsumi Y, Osamura RY, Watanabe K. Sclerosing stromal tumor of the ovary. Immunohistochemical and electron-microscopic demonstration of smooth-muscle differentiation. Archives of pathology and laboratory medicine. 1989;113(4):372-6.

3. Kim TH, Lee HH, Hong JA, Park J, Jeon DS, Lee A, Koh ES. Sclerosing stromal tumor in an elderly postmenopausal woman. Journal of Menopausal Medicine. 2014;20(2):80-3.

4. Chalvardjian A, Scully RE. Sclerosing stromal tumors of the ovary. Cancer. 1973;31(3):664-70.

5. Özdemir Ö, Sari ME, Sen E, Kurt A, Ileri AB, Atalay CR. Sclerosing stromal tumour of the ovary: A case report and the review of literature. Nigerian Medical Journal. 2014;55(5):432.

6. Gwin K, Mariño-Enríquez A, Martel M, ReyesMúgica M. Sclerosing stromal tumor: an important differential diagnosis of ovarian neoplasms in childhood and adolescence. Pediatric and Developmental Pathology. 2009;12(5):366-70.

7. Casanova J, Huang KG, Adlan AS, Chi CL, Abdullah NA. Ovarian Sclerosing Stromal Tumor in a Postmenopausal Woman. Journal of Gynecologic Surgery. 2013;29(6):303-5.

8. Lee CM, Lim S, Cho HY, Lee JS, Shin JW. Sclerosing Stromal Tumor of the Ovary in Postmenopausal Women: A Report of Two Cases. Journal of menopausal medicine. 2015;21(2):115-9.

9. Peng HH, Chang TC, Hsueh S. Sclerosing stromal tumor of ovary. Chang Gung medical journal. 2003;26(6):444-8.

10. Prat J. Pathology of the Ovary, Saunders, London, UK, 2004.

11. Boussaïd K, Meduri G, Maiza JC, Gennero I, Escourrou G, Bros A, et al. Virilizing sclerosingstromal tumor of the ovary in a young woman with McCune Albright syndrome: clinical, pathological, and immunohistochemical studies. The Journal of Clinical Endocrinology \& Metabolism. 2013;98(2):E314-20.

12. Park SM, Kim YN, Woo YJ, Choi HS, Lee JS, Heo $\mathrm{SH}$. A sclerosing stromal tumor of the ovary with 
masculinization in a premenarchal girl. Korean journal of pediatrics. 2011;54(5):224-7.

13. Liou JH, Su TC, Hsu JC. Meigs' syndrome with elevated serum cancer antigen 125 levels in a case of ovarian sclerosing stromal tumor. Taiwanese Journal of Obstetrics and Gynecology. 2011;50(2):196-200.

14. Lee MS, Cho HC, Lee YH, Hong SR. Ovarian sclerosing stromal tumors: gray scale and color
Doppler sonographic findings. Journal of ultrasound in medicine. 2001;20(4):413-7.

15. Chang W, Oiseth SJ, Orentlicher R, Agarwal G, Yahr LJ, Cayten CG. Bilateral sclerosing stromal tumor of the ovaries in a premenarchal girl. Gynecologic oncology. 2006;101(2):342-5.

Cite this article as: Gargade CB, Desai AY, Shirsat DC. Sclerosing stromal tumour of ovary. Int J

Reprod Contracept Obstet Gynecol 2016;5:2037-40. 